\title{
Developmental Biochemistry
}

National Cancer Institute

\section{Source}

National Cancer Institute. Developmental Biochemistry. NCI Thesaurus. Code C18733.

The branch of biochemistry concerned with biochemical changes that take place between fertilization and maturity. 